\title{
DEL ANDROCENTRISMO A LA RELACIONALIDAD
}

\author{
Diego Irarrázaval
}

\section{0}

LA EXPERIENCIA Y REFLEXIÓN DE GÉNERO trata los detalles de cada día y las grandes disyuntivas humanas. La sentimos en el cuerpo y en los esquemas de poder. Ella toca lo cultural, lo político, lo espiritual, lo afectivo, la relación con el medio ambiente.

La cuestión de género corresponde al varón y a la mujer (no es pues un «tema femenino»). Se trata de una perspectiva y acción transformadora de relaciones humanas y de formas históricas; son factores relevantes para la teología y la espiritualidad. Esto es lo que deseo indagar.

\section{Problemática teológica}

Se trata de una visión y praxis (por eso no concuerdo con quienes reducen el género a una comprensión de la realidad). En concreto, me preocupa cómo ello redimensiona la práctica teológica.

J.B. Libanio ha recomendado: «A consideração do genero em toda a teología; isso implica que o binomio cultural masculino $e$ femenino em sua relacao se faz lugar hermeneutico da 


\section{DIEGO IRARRÁZAVAL}

revelação»'. Los varones ¿seremos capaces de tal radicalidad? Es algo complicado y cuestionador, pero es necesario y hermoso. Se trata de abandonar el modo androcéntrico de hacer teología, a fin de pensar la fe de modo relacional.

\section{Subjetivismo moderno}

Seamos honestos. La teología de liberación ha sido hecha desde una particular subjetividad occidental (un ser humano racional y con vocación a la libertad); esto conlleva una postura androcéntri$\mathrm{ca}^{2}$. En términos generales, la teología moderna es llevada a cabo por un sujeto que piensa a Dios en la historia; ella devalúa otras imágenes de Dios: creación, sabiduría, sensibilidad, comunidad, cultura, religión de cada pueblo, etc. También ella ha descalificado el imaginario del cosmos sagrado (como algo contrapuesto a la revelación bíblica). Dios ha sido representado sobre todo con ropajes patriarcales.

Pero hay excepciones. Unos cuantos teólogos y teólogas nos acercamos a Dios fuera del esquema antropo/andro/céntrico. Me parece que la meta no es pensar un objeto trascendente. Lo que nos apasiona es contemplar, gozar, reflexionar, poner en práctica el misterio de Amor. Dios no es un objeto que sería enjaulado por la mente de un sujeto unilateral (usualmente androcéntrico).

\section{Sabiduría relacional}

Vivo en el altiplano del Perú; aquí -entre otras cosas- se desenvuelve un pequeño círculo de género (varones y mujeres, indígenas y no indígenas). Vemos que en este mundo andino no existe un sujetoindividuo ni un objeto-cosmos. Sí existen entidades en interacción, y todo tiene calidad viviente. Sobresale pues la «relacionalidad».

1 João Batista Libanio, "Trinta anos de teología», en L.C. Susin (Org.), O mar se abriu, Sao Paulo, SOTER/Loyola, 2000, 146.

2 Estos primeros párrafos reproducen unos trozos de mi ensayo «Género y cultura en la teología» (en prensa en libro del DEI, Costa Rica); ver también mi "Perspectiva de género en la teología», Boletín de EATWOT-ASETT, I (1998), 3-7. 
Un amigo ha escrito: «En la polaridad (sexual) de mujer y varón (que no es un dualismo ni una dualidad excluyente), el universo tiene su expresión más densa y básica, sobre todo a través de la forma ritual y celebrativa ${ }^{3}$. Me parece que estas pautas redimensionan la teología cristiana. La realidad sexual y de género afecta la comprensión del universo y los modos de hablar y celebrar a Dios. Somos corresponsables del cosmos. Estamos relacionados/as entre nosotros/as, y correlacionados con la divinidad. Cabe, pues, hacer teología de modo relacional.

\section{Acción holística}

Algunos varones hemos sido estremecidos e inmensamente enriquecidos por la perspectiva de género y su proyecto de generar una nueva humanidad en la Tierra. ¿Es un paradigma más, una hermenéutica más, añadida a otras? No lo veo así. Se trata de algo muy fundamental y pluridimensional. El género marca nuestras identidades, las relaciones de poder, estructuras de convivencia humana, modos de pensar y actuar; también marca nuestra corporeidad espiritual y nuestra experiencia -como varón y como mujer- de Dios. Hay pues buenos motivos para que la acción/visión de género pueda iy deba! hacerse presente en cada elaboración teológica 4 .

Por consiguiente, no se trata de un esquema teórico que sería yuxtapuesto a los demás. Tampoco se trata de pensar (desde la fe) unas realidades de género. Más bien, es una labor concreta, teórica y práctica, con un carácter holístico.

3 José Estermann, Filosofía andina, estudio intercultural de la sabiduría autóctona andina, Quito, Abya Yala, 1998, 208.

${ }^{4}$ Agradezco muy sinceramente a quienes me ayudan a caminar por estas sendas del género; a comunidades andinas con sus formas de reciprocidad; a amigas teologas latinoamericanas (Elsa Tamez, Ana María Tepedino, Ivone Gebara, Sonia Querino, Silvia Regina de Lima Silva, Luzmila Quezada, Adelaida Sueiro, Dora Canales, María Clara Bingemer, María Pilar Aquino, Ofelia Ortega y otras excelentes guías). Deseo colaborar en un trabajo teológico masculino. Al respecto hay pocos logros. Unas notables excepciónes: Leonardo Boff «O masculino no horizonte do novo paradigma civilizacional», en W. Boechat (org.), $O$ masculino em questao, Petrópolis, Vozes, 1997, 96-107; y trabajos realizados por la Conferencia de Religiosos/as de Brasil (y publicados por Loyola: "Masculino e Feminino», "Genero e poder", "Sexualidade», "Genero e identidade», en 1999 y 2000) con aportes de Marcio F. dos Anjos, Victor Hugo Lapenta, Edenio Valle y otros. 


\section{DIEGO IRARRÁZAVAL}

\section{Género en la teología}

Uno comienza a revisar los contenidos de la fe. Su meollo es la persona y obra de Jesucristo, liberador de la humanidad. Estos contenidos son acogidos y pensados por sujetos y comunidades de varones y mujeres. En otras palabras, la revelación y salvación cristiana son vividas y captadas desde la condición masculina y desde la condición femenina, en la co-relación de géneros y en la responsabilidad que ambos tenemos en el acontecer histórico y en el cuidado de la creación.

Esto parece obvio; sin embargo, los esquemas androcéntricos nos han tapado los ojos. En general, el sujeto de la teología y el modo de hacerla ha puesto entre paréntesis la realidad de género. En mi caso, me avergüenza la arrogante y totalitaria manera con que he presentado la fe, presuponiendo que mi modo de pensar era universal; es decir, no me daba cuenta de que lo hacía desde mi particular condición masculina.

Tenemos, pues, en el género un inmenso desafío. Ello se suma a otros retos mayores, como son la opción evangélica por el pobre, el porvenir del medio ambiente, al que está atenta la teología de la creación, la ética cristiana articulada a alternativas locales y globales.

Si en toda la teología se trabaja con perspectiva de género, van apareciendo más hondas comprensiones de la presencia misericordiosa, de la palabra profética ante la violencia cotidiana, de la obra salvífica en el ambivalente acontecer humano. Esta perspectiva ya está dando frutos sólidos y sabrosos. Resaltan los estudios bíblicos, históricos, doctrinales, éticos y espirituales hechos por mujeres teólogas. Pero, insisto, no es un «asunto de mujeres». La práctica y perspectiva de género nos involucra a todos, varones y mujeres, y nos permite replantear la actividad teológica.

Por eso, al encarar esta amplia problemática, lo hacemos con sólidas convicciones y creencias, y con un proceso personal.

\section{ANOTACIÓN PERSONAL}

Podría relatar mis diálogos y cortocircuitos con la teología feminista, mis terremotos personales al estar asumiendo la visión/acción de género, mi búsqueda de relaciones justas tanto con la mujer como 
con el colega varón. Cada persona -que ingresa a la reflexión/práctica de género-vive unos cambios profundos.

\section{Re-engendramiento}

Mi vivencia puede ser resumida así: ser re-engendrado en mi condición masculina ${ }^{5}$. Es un re-nacer de carácter correlacional; prefiero llamarlo re-engendramiento, ya que junto con otras personas adultas estoy renaciendo (como anoto en la sección cuarta). A partir de esto veo posible reconfigurar la tarea teológica que llevo a cabo desde mi particular masculinidad.

Nos cuesta muchísimo morir al androcentrismo (itanto a varones como a mujeres!). Nos exige honda conversión en todos los aspectos del andar humano y en la aventura de la fe pascual. Dicha "muerte» o "conversión» me parece indispensable para ser felices. Voy a comentar este proceso lento y constante de ser re-engendrado.

\section{Morir para vivir}

La práctica de género me reinserta en la bella espiritualidad pascual. Es un morir para vivir más feliz. Es un proceso humanizador y trascendental. En esto -como en toda fe radical- constato la verdad del mensaje evangélico: «Si el grano de trigo muere... da mucho fruto» (Jn 12,24).

También se trata de zanjar con la modernidad androcéntrica y patriarcal (es decir, renunciar a mucho más que un machismo). Esto lo hago a fin de sanar el ser masculino, de descubrir una masculinidad emancipadora y relacional. A fin de cuentas, hay que reubicar lo masculino y lo femenino en la gestación de una nueva humanidad. iTodo esto vale la pena!

${ }^{5}$ A continuación retomo buena parte de mi ensayo «Si el grano de trigo muere... da mucho fruto; impugnación de lo macho, a fin de ser un hombre cristiano"; a partir de mis ponencias en eventos de género en Curicó (Chile) y Bogotá (Colombia) en 1999. 


\section{DIEGO IRARRÁZAVAL}

En los debates sobre género, muchos ponen el acento en la construcción histórica de las identidades, que se contrapone a la ingenua postura esencialista (que trata asuntos de género como diferencias predeterminadas). También hay ensayos posestructuralistas que discuten la noción de sujeto. Otra postura (con mayor peso teórico y práctico) es la relacional: lo masculino y femenino son entendidos de modo dinámico, y esta postura reconoce diferencias de género y también de raza, estrato social, generación, etc. ${ }^{6}$. Me siento en sintonía con esta última visión, por ser una postura holística.

Esta actitud holística puede formar parte de una espiritualidad humanizadora. A mi modo de ver, la «relacionalidad» engendra algo nuevo y profundo, tanto en el varón como en la mujer.

No se trata de una confrontación estéril (hombre versus mujer y viceversa), de una actitud superficial. iNo! Más bien es una espiritualidad nueva, trascendente, concreta. Al revisar mi trayectoria (y la de otros varones), veo que lo masculino puede ser re-engendrado en la interacción entre varón y mujer, y en vínculos no agresivos entre varones. Así, cada cual va renaciendo y forjando una humanidad con dimensiones diferentes y reconciliadas. Todo esto es distinto a una simple y voluntarista "construcción» del género masculino. Es pues una buena y genuina muerte, a fin de vivir más plenamente "con" $y$ "para" otros $y$ otras.

${ }^{6}$ Dialogando con Alzira Munhoz (20-21/5/999, en Sao Paulo) y con Marcela Lagarde (18-22/8/1999 en Bogotá) he reconocido distintas posturas de género; les agradezco sus iluminaciones. Para el debate teórico ver: Margarida Brandão y María C. Bingemer, Mulher e relaçoes de genero, São Paulo: Loyola, 1994; Luz G. Arango, Magdalena León, Mara Viveros (comp.), Género e identidad. Ensayos sobre lo femenino y lo masculino, Bogotá: Tercer Mundo/Universidad Nacional, 1995; Ursula King (ed.), Religion and Gender, Oxford, Basil Blackwell, 1995; Juan C. Callirgos, Sobre heroes y batallas, los caminos de la identidad masculina, Lima, Escuela de Desarrollo, 1996; Ronald Levant, Masculinity reconstructed, New York, Penguin, 1996; Marcela Lagarde, Género y feminismo, Madrid: Horas, 1997; Mara Viveros, «Los estudios sobre lo masculino en América Latina», Nomadas 6 (1997), 55-65 (Bogotá, Universidad Central); Walter Boechat (org.), $O$ masculino em questão, Petópolis: Vozes, 1997; Teresa Valdes y José Olavarría (eds.), Masculinida= des, poder y crisis, Santiago: ISIS, 1997; Pierre Bourdieu y otros, La masculinidad, Quito, Abya Yala, 1998; María Gonzales, Miriam Nuñez (coords.), Mujeres, género y desarrollo, Michoacán, Univ. San Nicolás de Hidalgo, 1998; Sonia Montecinos (comp.), Género y epistemología, Santiago: LOM, 1999; VV.AA., Antología latinoamericana y del Caribe: mujer y Género, 2 vols., Managua: UCA, 1999. 


\section{Trasfondo del proceso}

Mis vivencias se desenvuelven en el marco de la historia del pobre, con sus culturas y religiones. Ha sido una experiencia de diálogo y confrontación con «lo otro»-cultural y religioso- de pueblos pobres. A partir de esto, también me voy acercando a la "otreidad" del género. Durante muchos años he dialogado (y crecido personalmente) con formas culturales y religiosas distintas al esquema hegemónico. Gracias a ello ha sido posible ingresar a los replanteamientos de género.

Vale la pena transformar la condición masculina y la femenina. Esto requiere, para uno que es varón, una ascética cotidiana y una ruptura con estereotipos. Se derrumban certezas y privilegios. En términos positivos, uno va desarrollando una cálida libertad interior. El proceso es complicado, pero es liberador.

Tengo que añadir que, en mi caso, este proceso de ruptura y de liberación es vivido desde la orientación heterosexual y desde el misterio del celibato que opta por la vida del pobre. Cada persona se plantea el género desde sus rasgos personales, creencias, situaciones sociales y culturales. Comparto mis perspectivas particulares. Me parece muy rico confrontar las diversas experiencias. Uno no puede sobreponerse a otras vivencias. En esto -como en lo demáslo importante es la relacionalidad a favor de la vida plena.

También cabe ubicar los asuntos de género en el marco del cambio de época. Estamos delineando y respirando una civilización nueva. Ésta es mi siguiente anotación.

\section{Propuesta civilizacional}

En ambientes progresistas, uno constata confusión e inercia con respecto al porvenir humano. Crece la indiferencia hacia lo sociopolítico y, correlativamente, es exaltada la satisfacción subjetiva. Ésta no es la actitud de quienes estamos hastiados con un mundo que produce multitudes empobrecidas y parametradas. De varias maneras, hay muchos/as que silenciosamente colaboramos en pequeñas y grandes iniciativas de vida más plena. Los parámetros androcéntricos nos hacían planificar el cambio de modo uniforme y con sujetos omnipotentes. Nuestra actual opción es por un proyecto pluriforme y relacional, llevado a cabo por pequeñas hormigas. 


\section{DIEGO IRARRÁZAVAL}

\section{Globa-nacio-local}

Se trata de un anhelo y una apuesta multiforme. Es una propuesta civilizacional. Digo que es multiforme dados los distintos factores globales, nacionales y locales. Una propuesta realista también brota de las identidades, generaciones, culturas, políticas, razas y religiones. Otros factores son las maneras de ser masculino y femenino en cada contexto y trayectoria cultural. Siendo una propuesta plural, es más rica y compleja. Tiene una gama de protagonistas, e incluye el reto de generar alianzas y redes entre sujetos y realidades diferentes.

Tomando en cuenta la globalización, una propuesta de fondo no puede encerrarse en lo sectorial y nacional; más bien sumamos fuerzas a fin de continuar generando una civilización solidaria, en todo el planeta y a nivel local. Así como los fenómenos actuales son globales/nacionales/locales, asimismo las alternativas tienen que ser «globa-nacio-locales». Esto no lo hacen unos gigantes omnipotentes, sino una red de personas solidarias; no lo hace un macho todopoderoso, sino una correlación eco-humana en que el aporte masculino es entretejido con el femenino.

\section{Labor de hormigas}

Somos como hormigas involucradas en un inmenso cambio de época. Por un lado, tenemos el modelo hegemónico: economía neoliberal y planetaria, patriarcado, uniformidad en el consumo cultural, populismo político, etc. Por otro lado, existen señales de "otras» sensibilidades y proyectos y pueden reconocerse esbozos de una nueva civilización eco-humanista a escala local y mundial. Lo primero puede ser comparado con la arremetida de un feroz toro; lo segundo es semejante a la labor de millones de hormigas.

iCreo en la fecundidad de políticas-comunidades-hormigas! Las hormigas aseguran que el cambio de época sea constante, que sea desde lo cotidiano y lo pequeño y que se hagan grandes obras. Todo esto es a favor de la humanidad y la tierra; ellas están siendo expoliadas por el modelo hegemónico. Es necesario un cambio, no cosmético ni unilateral, sino más bien civilizacional. Las tercas e infatigables hormigas lo están llevando a cabo. 


\section{Pequeño y a largo plazo}

¿Cuáles son las fuerzas alternativas? Me parece, en primer lugar, que son señales minúsculas, fragmentos que pueden conjugarse, protestas ante medidas opresoras, iniciativas locales a favor de una justa convivencia humana. También veo una acción a largo plazo. Se trata de colaborar a la integridad de la creación, de crecer a partir de las diferencias y del derecho a la igualdad, de afianzar una ética solidaria, de desarrollar lo material con calidad espiritual, de celebrar la vida sin exclusiones.

Por lo tanto, a lo pequeño sumamos la estrategia a largo plazo. Lo segundo (sólido y estratégico) es inseparable de lo primero (pequeñas y frágiles iniciativas). Son palabras de cada día y también palabras grandiosas. Se refieren a lo cotidiano y aparentemente insignificante $y$, a la vez, a la constante elaboración de sentido utópico. Existen muchas prácticas y lenguajes que apuntan a modos de ser y estructuras alternativas.

Así lo constatamos al escuchar voces realistas y proféticas en varios lugares del mundo 7 . En Lima se afirmó una economía solidaria (superando neo-fatalismos ante la economía hegemónica). En Europa la red KAIRÓS ha subrayado alternativas a pequeña escala. Desde la Amazonía, Pedro Casaldaliga, en una de sus proféticas cartas, alaba la proliferación de proyectos alternativos y añade la necesidad de una «civilización alternativa». Desde Centroamérica, Xavier Gorostiaga visualiza una "época geo-cultural» del 2000 al 2020. Son voces de personalidades que recogen el clamor por la vida de tantas personas anónimas.

7 Simposio Internacional "Globalización de la solidaridad» (Lima, Julio de 1997): "una multiplicidad de actores que busquen su articulación tanto en el plano nacional como internacional (sección II); Documento KAIROS Europeo, Junio de 1998 (en especial la sección IV: acciones con alternativas a pequeña escala); Pedro Casaldaliga, "Final de Milenio» (carta de 1999): «una civilización alternativa...ensayo y fruto de muchos proyectos alternativos, de muchas buenas voluntades sumadas»; Xavier Gorostiaga "Hacia una prospectiva participativa» (ensayo, 1999): "una perspectiva 'gloncal' (global-nacional-local) desde abajo y desde adentro de la globalización...con fuerzas y actitudes creadoras de futuro". 


\section{DIEGO IRARRÁZAVAL}

Vale reiterarlo: existen propuestas alternativas, que suelen ser pequeñas y que están llamadas a conjugarse y constituir un proyecto a largo plazo. Así vamos avanzando en la construcción plural de la nueva civilización local y global.

\section{Ubicación masculina}

Pues bien, al interior de esta apasionante creatividad, algunos vemos un auténtico replanteamiento de lo masculino. Ya no el superhombre que en un instante soluciona todo, sino más bien la pluriformidad, constancia, colaboración, al estilo de las hormigas.

Esta renovada masculinidad no es un asunto pragmático, subjetivo, emocional («yo me estimo y actúo sin oprimir»). Se trata de una propuesta holística en que uno, como varón, renace en la relacionalidad humana y en la responsabilidad histórica y ecológica. Ya he hablado del cambio civilizacional.

En este sentido van las lúcidas y precursoras anotaciones de Leonardo Boff. Desde hace años está hablando de la reconstrucción masculina en un proyecto humano, histórico, ecológico ${ }^{8}$. También es relevante la elaboración ecofeminista. Por ejemplo, Ivone Gebara hace tiempo aclaró que no se trata de sacralizar la naturaleza ni la mujer, sino de «buscar caminos alternativos de convivencia", y recientemente ha subrayado el concepto de relacionalidad que nos hace «soñar con un mundo en que la belleza y respeto por lo diferente sean capaces de rehacer las fuerzas de equilibrio de la vida»?.

Me parece que desde varios ángulos estamos visualizando un paradigma radicalmente bueno. Se trata de ser felices, como lo promete (y no lo concede) la modernidad. Ésta privatiza la existencia y pone obstáculos al deseo de ser personas mutuamente vinculadas.

${ }^{8}$ Leonardo Boff, «O masculino no horizonte do novo paradigma civilizacional», art. cit., 1997; su acertada crítica al antropocentrismo (que conlleva el androcentrismo) es hecha desde una propuesta de «religação, da sinergia, da logica da complexidade, da pan-relacionalidade» (págs. 97-101).

9 Ivone Gebara, Teologia ecofeminista, São Paulo, Olho d'Agua, 1997, 17, y Rompendo o silencio, Petrópolis: Vozes, 2000, 200. 
Hay que restablecer contactos con la naturaleza y el medio ambiente, a fin de que como humanidad sobrevivamos y gocemos la creación. La innovación tecnológica y científica puede orientarse a necesidades básicas de mayorías pobres.

También se trata de replantearnos las relaciones entre varónmujer, varón-varón, mujer-mujer, humanidad-medio ambiente. Esto se lleva a cabo en lo cotidiano y en formas de poder. En un sentido general, apostamos a la sana utopía "relacional», es decir, creemos en una nueva humanidad y existencia en la Tierra y el Cielo, donde diferencias de género, culturas, sensibilidades, razas, capacidad económica, etc. son orientadas al bien común y a la integridad de la creación.

Ciertamente, también anhelamos un crecimiento espiritual $e$ interreligioso. Quienes somos católicos deseamos fortalecer el ser y actuar eclesial según el Espíritu de Jesús. Por lo tanto, a fin de cuentas, ¿qué rasgos tiene el nuevo paradigma? Es un paradigma ecohumano-social-espiritual.

Esto lo digo con los pies en la tierra. No caben ilusiones de algo inmediato, obtenido por medios casi mágicos. Atravesamos un cambio de época y sentimos gran incertidumbre. Existen agudas contradicciones, despolitización y "yoismo", mimetismo e imitación de culturas supuestamente superiores, la lamentable cooptación de profesionales que se someten a un mercado totalitario, y tanto más que nos hace illorar de rabia! El escenario es desolador.

Pero en el desierto siguen creciendo minúsculas flores y se mueven hábiles insectos y seres humanos inteligentes. La alternativa está en las manos, corazones y sabiduría de las hormigas. Es decir, son pequeñas y frágiles las dinámicas de la vida humana, pero son muchas y bien coordinadas, como la labor de las hormigas. Ellas realizan obras increíbles. Con la tenacidad de las hormigas es posible afianzar nuestra propuesta civilizacional en medio de luces $y$ oscuridades.

\section{VARÓN RE-ENGENDRADO}

Para quien es varón -dentro del parámetro de ser fuerte, autónomo, con poder sobre los demás- es sumamente difícil asumir un nuevo engendramiento. Se trata de una revolución en lo más profundo, al 


\section{DIEGO IRARRÁZAVAL}

interior de cada persona y en el comportamiento cotidiano; un proceso a corto y largo plazo. Considero que este proceso modifica el ser creyente y también la labor teológica.

\section{Agradecimiento}

Ser re-engendrado es respirar libertad. Implica muchas cosas: apreciar nuestra sana debilidad, recibir, dar, compartir vida en vez de dominar, una adquisición de poder en la que crecemos reconstituyendo poderes, un dejar de ser autoritarios y pasar a ser una comunidad donde los varones descubrimos un liderazgo de carácter relacional, un aprender la interacción varón-mujer y entre varones, a fin de juntos ser re-engendrados y re-engendradas.

Esto ocurre de varias maneras. Tengo la experiencia de ser reengendrado -durante estos últimos años- en la amistad con mujeres (ino sumisas!) y con varones (icompañeros y no dueños del mundo!). Son vivencias-regalo que llegan al fondo de mi ser. Es una interacción en que disfruto el ser masculino en una "relación con" y una "relación para» la vida. Esto hace crecer a personas diferentes. No es uniformización ni menos aún clonación.

Agradezco de corazón a las personas concretas que me permiten desplegar esta vivencias, con todos sus interrogantes y retos. Estas personas me están haciendo renacer. Me regalan vida.

\section{Lineas y contextos}

Voy a trazar unas líneas de este nuevo ser masculino. No niega ni excluye a otra ni otro, ni me descalifico a mí mismo en la trayectoria personal. Es un itinerario de emancipación relacional.

Como una criatura va dando sus primeros pasos, tambaleándose y con ojos llenos de admiración, así siento que voy dando pasos inéditos. Esto ocurre en el plano del género: redescubro el ser masculino y el ser femenino con sus interacciones y sus estructuras. Con respecto a la sexualidad, ella incide en todo. En los diálogos sobre estos temas, constato la distinción que muchos hacen entre lo biológico-sexual y el género socio-cultural. Son distinciones válidas sólo en el plano analítico, ya que la realidad conjuga dichas dimen- 


\section{DEL ANDROCENTRISMO A LA RELACIONALIDAD}

siones; la sexualidad y el género son indesligables. En cada etapa de la vida, uno va dando pasos en la sexualidad y en la perspectiva de género. iEs saludable caminar!

Esto ocurre en los contextos en que me encuentro, tanto en el espacio andino, con su cosmovisión y praxis relacional, como en otros lugares del mundo. Los desafíos tienen rasgos contextuales en los distintos universos simbólicos. He sido criado en Chile, en un ambiente familiar $y$ social donde lo masculino era determinar la existencia de otras y otros y donde el sexo era mirado negativamente y conectado con el pecado. Mi vida adulta la he pasado en diferentes mundos culturales (con sus respectivos acentos masculinos) donde hay mayor transparencia sexual. Vale la pena reexaminar la trayectoria y contexto en que cada quien se encuentra.

Cada universo simbólico tiene sus procesos de elaboración del ser masculino y femenino, con sus logros humanizadores, con sus entrampamientos, con sus hipocresías y sus opresiones. En mi contexto, veo que la perspectiva de género se enriquece en la medida que es intercultural. Mi inserción en ambientes marginales hace posible apreciar lo femenino y lo masculino tanto en la mujer como en el varón pobre. Además, a quienes somos varones urbanos nos ilumina enormemente el comportamiento de género andino; es el caso de la reciprocidad económica y ritual entre varones y mujeres del mundo quechua y aimara; es un modelo de trabajar juntos y de celebrar la vida cogestionada. En el contexto urbano podemos ser re-engendrados si llevamos a cabo tareas económicas articuladas con lo espiritual, en el sentido de no dominar a los demás, sino colaborar en la acción cotidiana con su valor trascendental.

\section{O violencia o vida}

Uno va cuestionando roles masculinos. Nos hemos acostumbrado a ejercer mayor fuerza física y psicológica y descalificar a la mujer como frágil e insegura. iEsto no corresponde a la realidad! También ejercemos el rol de proveedor económico y conductor político de los y las demás. Suele ser un autoritarismo benevolente; el machismo es más eficaz cuando es sutil y benefactor (aunque a veces es burdamente agresor). También los varones nos autodesignamos el rol de 


\section{DIEGO IRARRÁZAVAL}

pensar y programar $y$ tachamos lo femenino como supuestamente irracional, espontáneo, caótico. Asumimos además el rol de competir y triunfar (tan importante en el neoliberalismo globalizado) y tanto más.

Pues bien, estoy examinando estos roles que me inhumanizan y me convierten en agresor. Y, a la vez, estoy desarrollando otros roles masculinos: compartir diferentes tipos de fuerzas y fragilidades, pensar y actuar de forma relacional, contribuir a éxitos personales y comunitarios.

Los roles que mencioné primero conllevan normas terribles. Siendo macho, uno es (iy debe ser!) autosuficiente y tiene el "derecho sagrado" de supervisar y controlar a los demás. También ha llegado a ser ley la fatal dicotomía entre sexo e intimidad, la separación entre sexo y comunión integral. Por otro lado, es norma reprimir lo femenino que hay dentro del varón. Nunca uno puede manifestar sensibilidad femenina ni debilidad, ni temor ni coraje femenino.iEsto ocurre tantas veces! Además, nos hundimos en una perversa autoafirmación, a costa del resto de la realidad; me refiero a que lo masculino es siempre conquistar y conducir a otras personas y estructuras, y ser un dominador de la naturaleza que sirve nuestros caprichos. La norma suprema es ser exitoso dentro del esquema androcéntrico (lo contrario es ser poco hombre o no ser hombre).

Considero una liberación, una "gracia de Dios", el haber comenzado a impugnar esos roles y leyes supuestamente sagrados e inmutables. Considero un don poder renacer y compartir la masculinidad plenamente humana. Esto se da a través de muchas experiencias concretas. Sólo anotaré rasgos generales.

El primer momento de la emancipación es confrontar la violencia. Uno reconoce a las víctimas, primeramente la mujer, y también uno que es varón; todo el mundo es víctima del patriarcado. A continuación, uno busca la regeneración del ser masculino. ¿Somos capaces de ejercer liderazgo en corresponsabilidad entre varones y con las mujeres? ¿Articulamos la inteligencia con la afectividad (tan reprimida), a fin de pensar con el corazón, con símbolos y con conceptos? Así lo estoy viviendo. Los resultados son fabulosos. Además, uno redescubre la ternura y ve el valor de la fragilidad. Tam- 
bién se va forjando una ética del cuerpo masculino y femenino, una ética de la corporeidad relacional, festiva, macrosocial y teológica, como la ha enunciado Marcio Fabri dos Anjos ${ }^{10}$. Otro gran rasgo de la masculinidad es colaborar en lo público e histórico, en procesos económicos y políticos, pero todo esto uno lo hace a partir de proyectos de vida de pueblos pobres. Es, pues, un itinerario polifacético.

\section{Modelos creyentes}

En este itinerario, uno se siente motivado por modelos de praxis y espiritualidad cristianas. Nuestra cotidianeidad como personas $y$ comunidades, con las diferentes formas de ser creyente y de responsabilidades en la Iglesia, puede ser desarrollada con una perspectiva de género. En mi caso, hablo a partir de lo que he ido compartiendo con el pueblo sencillo en varios lugares de América Latina. Disfruto, aprendo y me siento inspirado por personas ejemplares en su manera de ser varón y de ser mujer.

Uno también acoge modelos bíblicos. En primer lugar, veo nuevos desafíos para ser discípulo de Jesucristo. Para el caso de los varones, Jesús nos presenta un modelo de masculinidad. Es hijo de Dios encarnado a través del cuerpo y voluntad histórica de la mujer María de Nazaret; ello implica nuestra en-carnación en formas precisas.

Igualmente paradigmático es su trato con sus discípulos y discípulas, no en el rol autoritario y sacerdotal, sino dentro de su hermosa misión enraizada en la presencia amorosa de Dios. También resalta el trato liberador con la mujer postergada de su tiempo, y su inserción no jerárquica en el mundo cultural y religioso de su época. Lo fundamental es su modo humano de interactuar con Dios, que conlleva fe, ternura, praxis de la basileia. Cristo da testi-

10 Ver Marcio F. dos Anjos, "Por una nueva ética de la corporeidad", en W.AA., Vida, clamor y esperanza, Bogotá, Paulinas, 1992, 257-265; sus pistas paradigmáticas: "Encruzilhadas da etica teologica hoje» en VV.AA., Teologia $e$ novos paradigmas, Sao Paulo, SOTER/Loyola, 1996, 169-171; y su texto en la CBR (citado en la nota 4). 


\section{DIEGO IRARRÁZAVAL}

monio de la acción salvadora, que no excluye a quienes la sociedad de su época maltrataba de modo sistemático. Asimismo, uno puede sentir y actuar con la libertad de su Espíritu.

También María es modelo de valentía, nueva humanidad, fidelidad. Lamentablemente, la hemos exaltado y desfigurado debido al esquema patriarcal; ya no es mujer en su pueblo y fiel al Dios liberador, ha pasado a ser caricatura de sacrificio que sustenta la subordinación y violencia contra la mujer y la superioridad del varón. Como dice el teólogo José Ignacio González Faus: «Perdónanos, María, por tanto como te hemos desfigurado... así somos los hombres: que parece que no podemos querer si no es configurando al otro a imagen de nuestros pequeños deseos»" ${ }^{11}$. Uno puede añadir: ilumínanos, María, para ser fieles, de modo correlacional, a la salvación, como tú has sido fiel.

Ella es quien alimenta en uno -como varón- la faceta femenina y una renovada faceta masculina. Nos cabe un modo de ser masculino en relación de reciprocidad con la mujer, que regala vida. Ella también nos manifiesta lo femenino en Dios, como acota Lina Boff: "(ella) es símbolo que encarna la dimensión femenina de Dios» en la persona de Jesucristo ${ }^{12}$. Me atrevo a decir que los varones, al venerar a María, nos es posible reencontrar al Dios verdadero, con su modo de ser masculino y femenino. Adoramos a quien, siendo Dios, trasciende dichas categorías. A la vez, los varones podemos reasumir facetas femeninas. Doy gracias a Dios por esta praxis cristiana.

\section{Colaboración HOLÍSTICA}

Me disgusta tanto acento en "género" considerado como visión, reflexión, imperativo ético; a veces parece que fuera como una nueva "disciplina» de pensamiento y de moral. Por otra parte, algunas personas están subrayando lo psicológico (identidad de género) y lo político (de-construir y re-construir los poderes). Para mí lo básico es la práctica de género, en cada faceta y en el conjunto de la vida.

11 J.I. González-Faus, «No macular la Inmaculada», Carta a las Iglesias, diciembre 1998, El Salvador.

${ }^{12}$ Lina Boff, Maria e o femenino de Deus, São Paulo, Paulus, 1997, 10-12. 
Dicho creyentemente, me interesa el género en nuestra conversión y caminar histórico, de modo correlacional, hacia la basileia de Dios. Me preocupa, pues, la colaboración teológica en el modo de entender y comunicar la fe. ¿Cómo lo hacemos? Con astucia (ante la dominación) y con inmenso cariño.

\section{Astucia y ternura}

En primer lugar, es necesario ser astutos. La teología moderna desenmascarada por Juan José Tamayo- es hecha por «varones que operan en el marco de unas prácticas culturales y sociales androcéntricas "13. Ante esta realidad, ¿cómo actuamos los varones que forjamos estrategias alternativas? Bien sabemos que el poder dominante no tolera alternativas, las desfigura o las coopta. También sabemos, como explica Pierre Bourdieu, que la dominación masculina emplea la violencia simbólica; ésta constituye un hábito a menudo inconsciente y sustentado en condiciones sociales ${ }^{14}$. Por eso se requiere gran astucia para confrontar la violencia dentro de uno como varón y dentro de la sociedad envolvente y, para luego, trazar líneas nuevas.

Esta ardua labor también es llevada a cabo con ternura. Así es el estar cobijados y cobijadas por el maravilloso amor de Dios. Su presencia nos libera de esquemas androcéntricos. Por consiguiente, ¿cómo mujeres y varones nos estamos desencadenando? Uno desea ardientemente la emancipación de cada uno y una. Aún más, buscamos de manera conjunta una existencia amorosa. ¿Somos consecuentes con la ternura liberadora, dada por Dios y cultivada por nosotros y nosotras?

13 Juan J. Tamayo-Acosta, Teología, pobreza y marginación, Madrid, PPC, 1999, 81-2, donde añade: «para la teología moderna, el varón es el verdadero referente del género humano, la mediación privilegiada para el logro del ideal de emancipación y de realización plena de lo humano, así como el único capaz de representar a Cristo y de hacerlo presente sacramentalmente».

${ }^{14}$ Ver P. Bourdieu, «La dominación masculina», en Bourdieu, Hernández, Montesinos, La masculinidad, Quito, Abya Yala, 1998, pg. 24 y ss. 


\section{DIEGO IRARRÁZAVAL}

\section{Líneas de acción}

Se trata de una labor holística que conlleva varias líneas de responsabilidad eclesial y teológica. De nuevo repito que formulo líneas desde mi condición masculina. Mi aporte desea sumarse a lo que hacen otras personas, quienes han estado trazando desafíos e interpelaciones, ya sea desde lo femenino como de lo masculino. Ojalá mis preguntas y lineamientos animen a un mayor soñar, un pensar crítico, un festejar la vida de fe.

\section{Identidad con... y para...}

Uno es cristiano y hace teología desde su historia particular, identidad y proyecto de vida junto a otros y otras. ¿Estoy pensando desde la identidad masculina emancipada, en correlación con la identidad femenina? ¿Cómo lo hago en medio de un mundo violentamente androcéntico? ¿Es mi labor evangelizadora y teológica con-para-lahumanidad-tierra-nueva?

\section{Acción sociopolítica}

Desde sus inicios, la teología latinoamericana ha colaborado en la lucha contra la injusticia que empobrece a las mayorías. Hoy nos agobian unos contextos despolitizados, populistas, posmodernos y escépticos. Estamos ante cuestiones de un cambio de época, de reemplazar la globalización con una mundialidad de auténtica libertad. Pues bien, ¿qué tipo de política estamos reinventando desde la opción por el pobre enriquecida con la capacidad masculina y la fuerza femenina?

\section{In-inter-culturaciones}

Nuestras sociedades son pluriculturales y plurirreligiosas, en las que hay cierta tolerancia, pero también hay mucha discriminación. En estos contextos, la visión y acción de género alienta la interacción con otro y otra, respetando diferencias y colaborando para una vida plena. Dicha visión y acción nos conduce hacia la inculturación y el 
diálogo intercultural e interreligioso con otros y otras. En este sentido, nuestra reflexión de fe íncluye la in-inter-culturación y la gestación de una nueva civilización? La postura de género fácilmente entra en sintonía con otros modos de sentir y pensar la fe. Esto replantea el ser masculino, que de excluyente pasa a ser dialogante.

\section{Renovación eclesial}

Gracias a la práctica y perspectiva de género, vamos reformando la misión de la Iglesia. ¿Ésta se dedica menos a adoctrinar y moralizar y más a ser instancia eclesial de compasión, profecía y celebración? Por un lado, en la renovada pastoral de conjunto y en la necesaria revisión de la estructura macroeclesial, ¿cuáles son las iniciativas masculinas y las femeninas?; por otro lado, ¿existen relaciones de libertad en lo microeclesial, en la familia, en la comunidad de base?

\section{Ecumenismo universal y terrenal}

En América Latina, las diferentes religiones y los sectores indiferentes y a-religiosos, ¿podemos convivir fecundamente, podemos llevar a cabo tareas comunes a favor de la dignidad humana, de la integridad de la creación, de la polifónica invocación del Misterio? Gracias a la sensibilidad de género, en que la humanidad crece a partir de las diferencias, es posible un ecumenismo de verdad. Antonieta Potente me ha hecho ver que, gracias a la mística de género, se forjan personalidades ecuménicas ${ }^{15}$. Hablando con franqueza, isomos personas creyentes y hacemos teología de modo ecuménico? ¿Lo hacemos en relación con otros mundos religiosos y con quienes son indiferentes? ¿Somos personas ecuménicas en el cuidado de la Tierra, que es casa de todas y todos?

${ }^{15}$ Diálogo con Antonieta Potente, en Taller de Género de la Conferre de Chile (Curicó, 4/6/1999). 


\section{DIEGO IRARRÁZAVAL}

\section{Cristología sin androcentrismo}

La obra de Jesús de Nazaret no ha sido patriarcal, tampoco lo es la actual reflexión en torno al Salvador. A menudo, el cristocentrismo ha sido desvirtuado por el androcentrismo. Sin embargo, tenemos líneas alternativas. Hoy en América Latina existen varios ensayos de cristología desde lo indígena y lo afroamericano, desde la mujer, desde la fe del pobre ${ }^{16}$ En estas reflexiones Cristo no agrede ni excluye ni culpabiliza a la humanidad. Por el contrario, es nombrado como vida, como misterio de muerte y resurrección, como sabiduría y compasión, como presencia salvadora en el cosmos y la humanidad. ¿Seremos capaces de continuar descubriendo los rostros de Cristo en el actual caminar de los pueblos? ¿Qué aporta la renovada condición masculina y qué aporta la femenina y qué aporta la correlación entre ambas?

\section{Presencia del Espíritu}

Es la fuente de la aceptación del "otro y la otra», ya que el Espíritu está presente de modo sorprendente en diversas cualidades y dones humanos, y también es quien transforma la creación. En nuestro continente hay cada vez más labor teológica y acción evangelizadora de carácter pneumático, que impulsa el encuentro fecundo entre religiones y espiritualidades. Algunos trabajos sacan a luz el carácter femenino del Espíritu. A mi parecer, uno no puede atribuir lo masculino a Cristo y lo femenino al Espíritu; ambas realidades divinas son significativas y salvíficas tanto para mujeres como para varo-

${ }^{16}$ Ver ensayos latinoamericanos: Eleazar López, Cristología india y evangelización inculturada, México, CENAMI, 1997; Antonio A. da Silva, "Jesus Cristo, luz e libertador do povo afro-americano", en Existe um pensar teológico negro?, São Pablo, Paulinas, 1998, 37-74; Ivone Gebara "Quién es el Jesus liberador que buscamos?" y Ana Maria Tepedino "¿Quién dicen las mujeres que soy yo?" ambos ensayos en 10 palabras claves sobre Jesús de Nazaret, Estella, Verbo Divino, 1999, 149-188, 415-452; mi Teologia en la fe del pueblo, Costa Rica: DEI, 1999, 63-82; y mucha producción en el Tercer Mundo; ver por ejemplo: C. Nyamiti, Christ as our ancestor, Zimbabwe: Mambo Press, 1984; R.S. Sugirtharajah (ed.), Asian Faces of Jesus, London: SCM Press, 1993; Kelly Brown Douglas, The Black Christ, Maryknoll, Orbis, 1999. 


\section{DEL ANDROCENTRISMO A LA RELACIONALIDAD}

nes. Más bien me pregunto: ¿qué pasará en los próximos años, a medida que vamos ahondando en la pneumatología? Es probable que la visión y acción de género contribuya a dicho desarrollo y, a la vez, que el imaginario del género sea redimensionado por la pneumatología.

\section{Ética y espiritualidad relacional}

Las fuentes del quehacer teológico en América Latina han sido la solidaridad eficaz con el pobre y la experiencia del Dios vivo; de allí han brotado muchas vertientes y corrientes de agua fresca en la reflexión de fe. Considero que estos logros tienen que ver con una matriz relacional. El trabajo teológico no ha estado dirigido unilateralmente hacia el pobre ni se ha interesado sólo por lo espiritual; más bien han interactuado teología y pobre, sabiduría y espiritualidad. Estas correlaciones son lo importante. A ello contribuye la visión y acción de género, que forma parte del proyecto de nueva civilización. En este sentido vamos creando nuevas relaciones entre lo masculino y lo femenino, sin dominación. En términos positivos, vamos creciendo mutuamente gracias a las diferencias y las correlaciones.

\section{UNAS PALABRAS FINALES}

Si el grano de trigo no muere ino brota una vida nueva! Si muere, entonces sí podrá haber buenos frutos. En mi caso, agradezco al mundo indoamericano que me envuelve; gracias a él me entusiasma ser parte del terreno fértil de la humanidad. Me siento como un grano de trigo y estoy muriendo para revivir en la Tierra. Uno no fallece en el vacío. Más bien, uno abraza un misterio terrenal.

Me exijo a mí mismo, e invito a otras personas, a continuar luchando contra el encarcelamiento machista (donde nos encontramos cautivos varones y mujeres). Podemos ser re-engendrados en lo masculino y en lo femenino mediante una colaboración recíproca entre varones y mujeres. Esto forma parte de nuestros pequeños y grandes sueños. Nuestra apuesta es una civilización que 


\section{DIEGO IRARRÁZAVAL}

es forjada por la acción de hormigas. Veo que así estamos ingresando a una nueva tierra y un cielo nuevo, tal como Dios nos lo ha prometido.

Hoy cabe repensar la esperanza. En medio del mundo globalizado existen líneas alternativas. Hoy es reavivada la esperanza al transitar por un cambio de época. En este contexto, como varones y como mujeres, pensamos la fe. Ahondamos el amor cristiano, que supera las barreras sexistas. Celebramos al Dios liberador, que nos regenera el ser masculino y el ser femenino.

Todo esto ocurre en medio de dolores de parto (cf. $\mathrm{Rm} 8,22$ 23) de nuestros cuerpos, de la humanidad, del medio ambiente. El parto duele y es productor de vida. El parto marca un antes y un presente y porvenir. En este sentido, por una parte abandonamos una forma de teología antropo y androcéntrica. Por otra parte, el presente y el porvenir están dedicados a «pensar el Amor» de modo relacional. 